University of New Hampshire

University of New Hampshire Scholars' Repository

Sociology Scholarship

Sociology

6-1-1998

\title{
Ethnic identity and aspirations among rural Alaska youth
}

Carole L. Seyfrit

Old Dominion University

Lawrence C. Hamilton

University of New Hampshire, Durham, lawrence.hamilton@unh.edu

Cynthia M. Duncan

University of New Hampshire, Durham, Mil.Duncan@unh.edu

Jody Grimes

University of New Hampshire, Durham

Follow this and additional works at: https://scholars.unh.edu/soc_facpub

Part of the Sociology Commons

\section{Comments}

Seyfrit, C.L., L.C. Hamilton, C.M. Duncan \& J. Grimes. 1998. "Ethnic identity and aspirations among rural Alaska youth." Sociological Perspectives 41(2):343-365. Reprinted by permission of SAGE Publications. https://dx.doi.org/ $10.2307 / 1389481$

\section{Recommended Citation}

Seyfrit, C.L., L.C. Hamilton, C.M. Duncan \& J. Grimes. 1998. "Ethnic identity and aspirations among rural Alaska youth." Sociological Perspectives 41(2):343-365.

This Article is brought to you for free and open access by the Sociology at University of New Hampshire Scholars' Repository. It has been accepted for inclusion in Sociology Scholarship by an authorized administrator of University of New Hampshire Scholars' Repository. For more information, please contact Scholarly.Communication@unh.edu. 
AUTHORS' DRAFT. Final version published at:

Seyfrit, C. L., L. C. Hamilton, C. M. Duncan and J. Grimes. 1998. "Ethnic identity and aspirations among rural Alaska youth." Sociological Perspectives 41(2):343-365.

\title{
ETHNIC IDENTITY AND ASPIRATIONS AMONG RURAL ALASKA YOUTH
}

\author{
Carole L. Seyfrit \\ Lawrence C. Hamilton \\ Cynthia M. Duncan \\ Jody Grimes
}

This research has been supported by grants from the Arctic Social Sciences program of the National Science Foundation (DPP-9111675 and OPP-9319921). We also benefited from the assistance of Stephanie Martin, and from suggestions by several anonymous reviewers.

\begin{abstract}
The villages of rural Alaska comprise one of the most exceptional, yet least visible, sociocultural environments in the U.S. They are geographically remote, and set off from the mainstream also by their unique Eskimo, Indian or Aleut cultures. At the same time many economic, legal and cultural connections pull these villages toward the dominant U.S. society, impelling continual and rapid social change. Our research focuses on adolescents growing up in this culturally complex and changing environment. We employ survey data from adolescents in 19 rural schools to explore relationships between ethnic identity and students' expectations about moving away or attending college. Many students describe their ethnic identity as mixed, both Native and non-Native. On some key variables, the responses of mixed-identity students fall between those of Natives and non-Natives, supporting a theoretical conception of ethnicity as a matter of degree rather than category. Migration and college expectations vary with ethnic identity, but the college expectations/identity relationship fades when we adjust for other variables. Ethnicity affects expectations for the most part indirectly, through "cultural tool kit" variables including family role models and support. Gender differences in expectations, on the other hand, remain substantial even after adjusting for other variables.
\end{abstract}

\section{INTRODUCTION}

Alaska's bush villages seem in many respects a world apart from the rest of the U.S. Most villages are unconnected by roads, so that traveling anywhere - by airplane, snowmobile, boat (when water is liquid) or "ice road" (when it is not) - requires more effort, expense and risk than does routine travel in the lower 48 states. Winters are long and arduous, summers brief and buggy. Northern Alaska rivers thaw out in May or June, then freeze up again in October. Populations concentrate in small communities separated by wilderness. One town with a few thousand people typically serves as the regional transportation, government, and commercial hub for a number of smaller villages. For example, the Northwest Arctic Borough, one of our study sites, has about the same area as the state of Indiana, but a population of just 6,000 people - half of them in the hub town of Kotzebue, and most of the rest in ten smaller villages of 90-600 people.

Away from tourist circuits, jobs derive mainly from natural resources (oil, mines, fish or timber) and the large public sector. Like population, employment concentrates in the regional hubs, so that many smaller villages offer almost no full-time jobs outside of their schools. The schools' importance extends into many facets of village life. Schools are frequently the largest employer, the largest building in town, and the only place capable of housing a meeting or the socially crucial evening basketball games. A school might also 
have the village's most reliable power, water or plumbing facilities. When a generator providing electricity for the Northwest Arctic village of Buckland failed during bitter weather in March 1995, the school's own generator was pressed into service to supply the village until a new generator could be flown into an emergency airstrip created by clearing snow from the frozen river.

Many village schools offer high school degrees, although classes can be small. During the 1994-95 school year, 204 Alaska schools had 100 or fewer high school students; 91 had no more than 10 students (Hower and Kelly 1996). The availability of village secondary education has boosted graduation rates, but students graduating from such schools sometimes encounter difficulty in adapting to urban life or college. Questions concerning how well local schools prepare their graduates for life elsewhere, and whether better preparation for leaving is necessarily a good thing, are asked by village parents, educators and others (e.g., Alaska Federation of Natives 1989). At the state level, arguments often focus on the high costs of rural schooling. As North Slope oil fields become depleted, and the state revenues available to support bush schools correspondingly decline, political leaders increasingly ask whether the state can afford to have so many high schools in small villages. On one hand, schools connect these remote, relatively traditional communities with the larger economy and society, and maintain school attendance and graduation rates among village youth. On the other hand, discouraging reports about test scores, employment and postsecondary education raise doubts about the village schools' effectiveness (Hower and Kelly 1996; Kleinfeld 1992).

The population served by village schools — and hence, most affected by this debate - is predominantly Alaska Native, a designation encompassing Aleuts, Eskimos (Yupik and Inupiat), and Indians (mainly Athabaskan, Tlingit and Haida). Although Natives comprise less than $16 \%$ of the state's population, they make up 54\% in communities having fewer than 1,000 people. Many villages are more than $90 \%$ Native. Recent anthropological accounts of village Alaska, including books by Chance (1990) and Jorgensen (1990), emphasize the enormous changes wrought by North Slope oil development (also see Chance and Andreeva 1995). Other anthropologists including Fienup-Riordan (1990) and Condon (1987) describe life in contemporary Arctic villages. Their work underscores the great distances, cultural as well as geographic, separating Native villages from modern metropolitan areas. Nevertheless, they show that the villages too are experiencing rapid social change. A cash economy has largely replaced subsistence; television has become ubiquitous; housing, infrastructure and transportation have been revolutionized; and hundreds of new jobs have opened up, notably in construction (often temporary) and the rapidly growing public sector (more permanent).

These and many other changes fall particularly hard on young people, who grow up in a world so altered that it seems their elders' traditional knowledge ("grandpa with his harpoon" as one youth dismissively put it) no longer applies. In some households, the generation gap is also a language gap. Rural Alaska adolescents consequently form an important, but somewhat neglected, topic for research. This paper describes findings from a study of 9th-12th grade students in rural Alaska schools. We collected data on students' views of their present lives, and their goals and expectations regarding the future. Given the ongoing social changes, plus the impending fiscal constraints that reduce the state's ability to subsidize rural life, we are interested in the extent to which these young people see their future in cities, or aspire to attend college. One might expect that their plans would vary by ethnicity, with Natives more often planning to stay in rural Alaska or seek occupations that do not require college, and with non-Natives more inclined towards the white-dominated worlds of college and cities. That is, ethnic identity might affect youths' image of where they belong and what they should do.

Swidler's (1986) idea that people draw on a "cultural tool kit" when they make life-course decisions

helps to interpret our findings. In the following section we briefly review this concept. Next, we provide some background on public education in rural Alaska. Finally, we turn to an analysis of the student survey.

\section{CULTURAL TOOL KITS AND ASPIRATIONS}


Much of the literature, as Jacobs, Karen and McClelland (1991) point out, has adopted status attainment researchers' focus on socialization to explain differences in young people's aspirations. The premise is that some youth are encouraged by their families to aspire to college or professional jobs, whereas others are led to expect lower educational attainment and blue collar or even marginal, part-time work. Other scholars, including Bernstein (1971), Willis (1977), Bourdieu (1986) and Kerckhoff (1977, 1984) argue that aspirations derive not only from these expectations, but also from how young people experience the world. If people "like them" are not seen going to college or getting good jobs, that observation colors their own aspirations and plans.

This discussion is relevant to the question of how ethnicity might affect aspirations. For example, in what ways do aspirations of Alaska Natives differ from those of whites? Have ethnic differences meant different upbringings and traditions, leading young people to absorb different expectations and goals? Have those young people experienced different paths to adulthood in their immediate families and communities? Swidler's (1986) cultural tool kit idea combines aspects of socialization with the notion that one must have "an image of the kind of world" in which one might aspire to participate — be it higher education or urban living or a certain kind of job. Swidler argues that individuals have a kind of tool box of cultural knowledge and experience - habits, skills, even stories and world-views - that is acquired through everyday living in families, schools, social networks, and neighborhoods. These symbols and world-views not only represent a sense of present identity, for example as Aleut, Yupik or white. They also shape one's sense of what is the appropriate or desirable future, and thus aspirations. Swidler uses the example of a young ghetto boy being asked why he does not aspire to be a physician - he replies "Who, me?" She argues that the choice is unfamiliar rather than unwanted. What the boy knows does not include the style, skills and role models that would make such a choice even appear. For some Alaska Natives, particularly those surrounded by elders who have not experienced formal education, such ideas as career, city life or a college education might seem equally foreign. Other goals and outcomes, such as traditional skills or life closer to home, might receive higher value. But now, wherever they live, young Alaskans face a changing environment, much as immigrants face a new world with new rules, opportunities and dangers.

Some recent work on immigrants' adaptation to American society examines how traditional ethnic norms and values may either facilitate or hinder successful integration (Zhou and Bankston 1994; FernandezKelly 1995; Portes and Sensenbrenner 1993). These analysts draw on Coleman's $(1988,1990)$ and Loury's $(1977,1987)$ concept of social capital to describe the norms and relationships within the family, and between the family and the community in which it is embedded. For Coleman these norms and relationships can be resources that facilitate action, as does Swidler's tool kit. Indeed, the norms and relationships that make up social capital - immediate family, extended kin, friends and community networks - affect how the tool kit is filled, and thus images of who one is, where one fits and what one can become (McLanahan and Sandefur 1994; Duncan 1996). Zhou and Bankston (1994), for example, found that traditional values and norms that favor hard work and dedication to family — which they call social capital — could guide secondgeneration Vietnamese youth toward successful adaptation to American culture, including academic achievement and college plans, and help them avoid pitfalls of street life in poor neighborhoods. In their view traditional Vietnamese culture offered clear guidelines for action, but did not conflict with mainstream American culture.

For some of the Alaska Native individuals in our study, there might be less congruence between traditional and mainstream norms and values. Attending college or moving to a city would seem to require not only the usual attributes of ambition, self esteem and independence, aspects of the personality developed through socialization and family dynamics (Furstenberg and Hughes 1995; Spencer and Markstrom-Adams 1990), but also a readiness for acculturation. In bush villages, traditional values and norms support subsistence hunting and fishing, community life, and the maintenance of family connections. College or migration require one to step away, at least partially, from these familiar activities, places and people. Consequently, youth who plan to leave demonstrate an openness to acculturation. We can hypothesize that 
this openness has been affected by their family's background and expectations, that is, by their cultural tool kit. 


\section{PUBLIC EDUCATION IN RURAL ALASKA}

The dispersed population of rural Alaska complicates the design as well as the delivery of secondary education. Before 1976, few Native communities possessed high schools. Students wishing to pursue their education had no choice but to leave home, most often for the state-run Mt. Edgecumbe boarding school in Sitka - over 1,000 air miles from northern Alaska. Dislocation and the adjustments to boarding school were difficult, painful experiences for many students. As adults, they did not want to see their own children repeat these experiences.

A lawsuit brought to end this practice led in 1976 to a settlement that transformed rural Alaska education. The state agreed to provide high schools in any community requesting one, as more than 100 soon did. With the advent of village high schools, Native graduation rates improved dramatically, but new difficulties arose as well. The bush schools are expensive. Per-pupil expenditures in 1993 were about $\$ 12,700$ in the Northwest Arctic Borough, for example, and \$34,000 in the Aleutian Region, compared with $\$ 5,900$ in Anchorage, the state's largest city (Knight 1994). Furthermore, even such expenditures could not provide village students with the variety of resources, activities, courses or teachers that they should encounter in a larger high school. Reinforcing suspicions of a qualitative gap, standardized test scores in many rural districts remain well below national averages - although Alaska students' scores as a whole tend to meet or exceed national standards (Kleinfeld 1992).

The increasingly evident limitations of small schools led to a reconsideration and re-opening of Mt. Edgecumbe, as well as new debates about the desirability of starting other, regional boarding schools to provide an in-between alternative for students from villages. Village schools retain a strong constituency, however. Any boarding school proposal threatens to compete with local schools not only for funding, but also for top students, who one principal described as the "positive leaders" - a crucial human resource, especially in small communities. At present, local schools or Mt. Edgecumbe remain the chief options for most rural high school-age students.

Alaska public schools are organized into 54 school districts of three general categories: first-class cities (18); organized boroughs, somewhat like counties in other U.S. states (16); and a remainder organization, Rural Education Attendance Areas (23).[1] The districts, regulated by locally elected school boards, have considerable autonomy. Even within a single district, we found substantial differences between specific schools on such basic questions as, What is high school for? Should it aim primarily to prepare students for adult life in their home communities, whether jobs exist there or not? Or should schools prepare them instead to compete for jobs and training elsewhere? The diversity of Alaska schools' educational philosophies reflects the geographic and cultural diversity of the state itself.

The study described in this paper concentrates on 18 schools in four rural school districts, plus the Mt. Edgecumbe High School. To put the studied schools in their statewide context, Table 1 offers some statistical comparisons (data compiled from federal and state sources by Grimes 1997). Our rural study-area schools tend to be significantly more expensive, because they are relatively remote. Their communities have fewer adults with high school diplomas; fewer whites; and many more students living below the poverty line. Turnover among school personnel, often mentioned as a problem with local schools, was not significantly higher in the study area - but note that it did stand at 16.5\% in a single year. Income, unemployment and student transfers also show the expected, but nonsignificant, differences.

$$
<<\text { Table } 1 \text { about here }>>
$$

One noteworthy comparison from Table 1 involves graduation rates, which are basically the same in the study districts and elsewhere in Alaska. Equalization of rural and urban graduation rates has been viewed as a central achievement of the new rural schools. This achievement has been accompanied, however, by markedly unequal outcomes on standardized tests. Figure 1 shows the mean percentages of 8th graders scoring in the top quartile on standardized reading tests, 1989-95. On average, around 10\% of the study-area students scored in the top quartile, compared with about $25 \%$ of students in other districts. Reading, mathematics and language exam results for 4th, 6th and 8th graders over these years exhibit similar 
overall patterns, or the reverse patterns if we look instead at bottom-quartile students (not shown; see Grimes 1997 for original data sources).

$$
<<\text { Figure } 1 \text { about here }>>
$$

\section{THE ALASKA YOUTH STUDIES}

During winter 1992, Seyfrit and Hamilton conducted a survey of high school students in 15 rural Alaska schools. Their primary interest lay in exploring the impacts of rapid resource development on adolescents in remote Native communities. The study encompassed two regions (Northwest Arctic and Bristol Bay), one of which had been recently affected by mining. Results from that survey, and also from a second survey of recent high school graduates, have been described in several articles (Seyfrit and Hamilton 1992; Hamilton and Seyfrit 1993a, 1993b, 1994a). They had expected to find substantial differences between students of the Northwest Arctic and Bristol Bay regions, some of them attributable to cultural factors and others to the impacts of mining development in the Northwest Arctic. Although there was indeed evidence of mine-development effects, the surveys also found many broad similarities across the two regions - including similar contrasts within each region between students living in small villages and those in the more cosmopolitan hub towns.

One unexpected finding involved gender: female students more often reported that they hoped to move permanently out of their home region (Hamilton and Seyfrit 1993a). Furthermore, female high school graduates were more likely to have actually moved away (Hamilton and Seyfrit 1994a; also see Kleinfeld 1981, 1992; Kleinfeld, Gorsuch and Kerr 1986). Migration from Native communities of bush Alaska to larger cities moves one into a fundamentally non-Native environment, where a conscious effort is required to maintain elements of Native culture (Fogel-Chance 1993). The gender difference in migration translates into differences also in jobs, education, intermarriage and other life choices.[2] Several recent papers trace the scale of net movement using data from the 1980 and 1990 Census (Hamilton and Seyfrit 1994b) and older historical sources (Hamilton, Seyfrit and Bellinger 1997).

In March 1995, Seyfrit and Hamilton conducted a second survey to investigate questions raised by these and other findings. In addition to new questions it included coding to facilitate tracking students in the years ahead, creating the possibility that we can eventually learn how post-high school outcomes relate to students' earlier expectations and aspirations. The 19 schools covered by this second survey comprise all of those with 9th-12th grade students in four rural school districts (Northwest Arctic, Yupiit, Dillingham and Southwest), plus Mt. Edgecumbe High School.

Response rates in the four school systems studied ranged from $68 \%$ to $99 \%$ of all grades $9-12$ students enrolled. Three individual schools enroll over 100 students each (Kotzebue, Dillingham and Mt. Edgecumbe), but the others are smaller with about 6 to 40 students. These 19 schools yielded 762 usable questionnaires. Preliminary results including regional comparisons on a variety of open and closed-ended questions have been reported elsewhere (Seyfrit, Crossland and Hamilton 1996; Seyfrit and Hamilton 1997). In this paper we focus in more detail on students' perceptions of their own ethnic identity, and examine how identity relates to migration and college expectations.

During course of this study, researchers made repeat visits to all of the 19 schools and their communities, speaking with school board members, administrators, teachers, students and others. These extensive and varied conversations helped to "flesh out" the statistical picture, providing narrative accounts, meanings and possible explanations for what we found. The research team also used return visits as opportunities to give something back to the people under study, discussing with them both the actual findings and the process of survey research. 


\section{ETHNIC IDENTITY}

For official purposes at the district, state or federal level, "ethnicity" has been conceived as a set of mutually exclusive categories. An individual might be identified, or asked to self-identify, as either an American Indian/Alaska Native or as a member of some other category such as Hispanic or white. Of course, many people actually have mixed ancestry. Ethnic complexity is salient in rural Alaska communities for several reasons. First, mixed marriages (most often white male/Native female) form an important component in the female outmigration that shapes the demographics of many villages, as Native women leave with their white spouses (Hamilton and Seyfrit 1994b). Second, non-Native relatives may be better positioned to help children with information, skills, contacts and other resources needed for the changing modern environment, including the possibilities of college or urban life — aspects of their cultural tool kit made available through their social capital. Third, the proportion of people with mixed Native/non-Native roots varies across communities, and so might community norms and values about leaving the region and the benefits of college. We have heard differences between the politics or schools in two communities attributed to one community having "more white influence" than its neighbor, even though both communities appear ethnically similar (above 90\% Native) in Census data. What the speaker meant was that a higher proportion of the first community was ethnically mixed.

To allow students more freedom in characterizing their own ethnicity, our survey included the question listed, together with response percentages, at the top of Table 2. Students could check more than one answer in either of the first two columns, and add explanation in the third open-ended part. Overall about $62 \%$ of the students chose answers only within the Alaska Native column; $11 \%$ chose answers only within the non-Native column; and 22\% identified themselves as both Native and non-Native.

$$
<<\text { Table } 2 \text { about here }>>
$$

These survey responses paint a picture of the students' ethnicity that differs from that given by official statistics. Figure 2 contains a pair of bar charts for each of four different school systems. The left bar in each pair shows the ethnic self-identification - simplified to Native, both, or non-Native - of our survey's high school students. The right bar in each pair shows the officially-reported student composition for that school system as a whole (from Knight 1994, drawing on the U.S. Census), simplified to Native or non-Native. It appears that many students usually classed as Native will identify themselves instead as "both," when given a choice. Furthermore, the fraction doing so is greater in more cosmopolitan communities such as Mt. Edgecumbe boarding school or the hub town of Dillingham, than it is in villages such as those of the Southwest or Yupiit schools. A similar pattern holds true regarding the Northwest Arctic school district, including its hub town of Kotzebue (not shown). Thus, with ethnicity as well as with other variables from the 1992 survey, the 1995 survey finds that between-region differences among the rural Alaska places studied tend to be less striking than their common patterns of within-region differences, between larger towns and the smaller villages.

$$
<<\text { Figure } 2 \text { about here }>>
$$

\section{MIGRATION EXPECTATIONS}

One consistent result from both surveys has been the high proportion of students reporting that they want or expect to spend most of the rest of their lives outside of rural Alaska. These hopes and expectations are more widespread among females, and among town as opposed to village residents. Outmigration goals are important for several reasons. They express how adolescents see the desirability of life in their rural communities, as compared with cities elsewhere (the usual destinations mentioned). They also forecast potential problems for the future of towns and villages. On the other hand, many young Natives who leave these communities subsequently return, suggesting that there exist substantial discrepancies between what they anticipate and find in the cities.

Because most Natives living in rural Alaska were born there, and because life in these remote villages, including subsistence hunting and fishing, remains at the heart of cultural traditions, we 
expected to find an association between ethnic identity and migration plans. Figure 3 shows the empirical association, graphing by gender/ethnicity the percent of students expecting to spend most of the rest of their lives away from their present rural region (or their home communities, in the case of Mt. Edgecumbe's boarding students). Overall, $91 \%$ of non-Natives plan to leave, as do $79 \%$ of mixedidentity students and $60 \%$ of Natives.[3] Girls more often expect to leave than boys, but this gender difference is most sizable within the Native and mixed-identity groups.

$<<$ Figure 3 about here $>>$

\section{PLANS TO ATTEND COLLEGE}

In conversations with adult rural residents and educators, we frequently encountered ambivalent views regarding college. Some perceived college as a route that expands young peoples' choices, improving their chances of a happy life and financial independence while giving them more power to help their people or communities. Others expressed concern that college draws young people especially, potential leaders - away from the bush. It often trains them for jobs that do not exist in their home communities, and thus represents a step towards mainstream life. Moreover, both teachers and parents have seen many local graduates drop out after a short time at college, and so have good reason to question whether a college degree represents a realistic goal for many students.

Despite these doubts among adults in their communities, large majorities of the students said that they plan to attend college after high school. These included $91 \%$ of the non-Natives, $78 \%$ of the Natives, and $88 \%$ of the mixed-identity group, whose responses again fall in between. Figure 4 shows that a gender difference in college plans exists within each ethnic group, but it is greatest among Natives ( $87 \%$ of girls versus $68 \%$ of boys). As with out-migration expectations in Figure 3, we emphasize that this analysis focuses on what high school students say they intend to do; their eventual choices and outcomes will often be different.

$<<$ Figure 4 about here $>>$

College attendance in bush Alaska is possible without outmigration. In addition to correspondence courses, the University of Alaska Fairbanks (UAF) maintains six branch campuses that offer two-year Associate degrees as well as credits transferable towards main-campus four-year programs. Three of these branches (Bristol Bay in Dillingham; Chukchi in Kotzebue; and Kuskokwim in Bethel) have locations accessible to the town and village students we surveyed. Very few respondents mentioned these branch campuses, however. Those with specific college goals were much more likely to mention main campuses including those of UAF and the University of Alaska Anchorage, or out-of-state schools in Arizona, Oregon and elsewhere. We suspect that getting away from home is one of the perceived attractions of distant campuses - an appeal that the branch campuses, whatever their practical advantages, must lack.

\section{PREDICTORS OF COLLEGE ASPIRATIONS}

The first-order analysis of Figure 4 supports impressions from anecdotal accounts and previous research that ethnicity and gender predict students' college aspirations. But such background characteristics, by themselves, cannot provide causal explanations. Possible explanations for systematic differences in aspirations do arise from the literature on cultural tool kits reviewed earlier, or in the related literature on human and social capital. These explanations imply that we should see the ethnicity-aspirations relationship weaken once tool kit indicators are brought in as additional predictors.

Table 3 lists variables from the 1995 survey that will be used for this analysis. The dependent variable, college, records whether students said they plan to attend college or university after high school. For regression purposes our three-category ethnic identity variable has been re-expressed here as two dichotomies, native ( 1 indicating Native, 0 everyone else) and mixed ( 1 indicating mixed Native/nonNative, 0 everyone else). This makes the third ethnic category, non-Native, implicit when native $=$ mixed 
$=0$. Two demographic variables, gender and age, are included as controls and possible independent predictors of college.

$$
<<\text { Table } 3 \text { about here }>>
$$

The remaining variables in Table 3 represent aspects of students' cultural tool kit - although these five variables are by no means a complete operationalization, nor intended to fully test that theory. They should, however, help to explore how variables from this domain enhance our understanding of the ethnicity-aspiration relationship. All are items that were mentioned repeatedly as possible influences upon educational outcomes, during our discussions with educators and community members while we were designing the questionnaire. Table 3 distinguishes two subsets among the tool-kit variables: the respondent's individual, self-assessed competence (school grades and Native language); and respondent's family support and role models (parents' and grandparents' expectations; parents' education). The individual variables might also be viewed as aspects of human capital, or individual skills and learning. The family variables, similarly, could be viewed as aspects of social capital, or kin networks and support relationships that help the individual succeed. Because our variables are measured through the respondent's own perceptions, and represent learned, socially prescribed attitudes or behavior, the "cultural tool kit" remains most useful as a unifying concept.

Self-assessed student grades and Native language skills reflect students' views of their own achievements and potential. The formal-education confidence, and secondarily the real skills and achievements, represented by grades should increase the likelihood of college aspirations, regardless of ethnicity, gender or age. On the other hand we might expect that the Native cultural identification represented by language could decrease aspirations towards the basically non-Native world of college.

Parents' education level (pared) has been widely viewed as an indicator of potential family support for higher education, and hence something that positively affects children's ambitions and achievements. We also have two direct questions, parents and grandpar, asking whether family members encourage respondents to go to college. Most previous studies have not considered grandparent effects, but in Alaska these seem important because so many Native adolescents are raised by their grandparents, or in extended-family arrangements where grandparents figure prominently.

To assess whether these tool kit variables help explain the relationship between ethnicity and college aspirations, we fit a series of logistic regression models summarized in Table 4. Model 1 is the simplest, including only ethnic and demographic variables as predictors. Native identity has a significant negative effect on college in this model. Mixed identity, as usual occupying an intermediate position, exhibits a nonsignificant but also negative effect. Model 1 also confirms previous findings that females are more likely to plan college, and older (higher-grade) students are less so. This age effect implies increasing discouragement or shifting goals as students progress through high school and decide that college is not in their future.

$$
<<\text { Table } 4 \text { about here }>>
$$

Model 2 in Table 4 includes two individual-competence questions, grades and language. Grades shows the expected positive effect; language's effect is close to zero. Native identity, gender and age remain significant predictors even after controlling for grades and language.

When we also include the family support indicators, however, in Models 3 and 4, the effects of both native and mixed contract. Neither ethnicity variable now has coefficients distinguishable from zero. At the same time, the overall fit of the model improves substantially: pseudo $\mathrm{R}^{2}$ goes from .10 to at least .26.[4] Parents' and grandparents' educational hopes for the respondent, as well as parents' own educational achievements, clearly matter. All show the expected positive effects on college.

Although it seems theoretically desirable to keep parents' education (pared) in our analysis, doing so is costly. Many students did not know the highest year of schooling completed by either of their parents. As a result of their missing values, we lose 133 cases - making Model 3's subsample less representative, and its estimates more likely to be biased as well as imprecise.[5] Consequently, our 
interpretation will focus mainly on Model 4, which includes the other two family variables but leaves out pared. Note that Models 3 and 4 reach substantially similar conclusions with respect to ethnicity, gender and the remaining tool kit predictors, however.

Table 4 supports several conclusions:

1. Tool kit variables, including student grades but especially family support — parents' education, and parents' or grandparents' educational goals for the student - explain much of the statistical association between ethnic identity and college aspirations. We infer that ethnic identity affects aspirations indirectly. Young people acquire from their families concepts of what is educationally possible and desirable for them. Views favoring college are acquired more often, but not exclusively, in the context of mixed or non-Native families.[6]

2. The gender difference in college aspirations, on the other hand, remains significant and cannot be explained by any of the other variables in these models. The earlier graphical analysis suggests that gender differences have the same direction, although not exactly the same magnitude, regardless of ethnic identity.

3. College aspirations decline with student age, even when we control for grades and family encouragement. This may reflect increasing realism, discouragement or simply new non-college goals, as students' high school careers progress.

4. Self-reported fluency in Native languages exhibits an unexpected positive effect on college plans, once we control for family variables. Although some students learn these languages from older generations at home, relatively new bilingual programs in the schools also reinforce language schools, and for many students represent their primary exposure. In this context, language fluency represents not just knowledge of traditional culture: it is partly an academic accomplishment, reflecting students' efforts or feelings of mastery at school.

5. Grandparents' support for a college education proves to be as important as parents' support. The effect of parents' and grandparents' views appears to be independent of how much education the parents themselves completed.

Our sample here is not large enough to provide much power for subsample analyses, or to overcome multicollinearity problems in testing interaction terms. For a better descriptive understanding of our findings, however, we repeated the model 3 regressions separately for each of the three ethnic groups. Results (not shown) were as follows:

Natives $(n=396)$ : $\quad$ Female, age, grades, language, parents and grandpar all significantly predict college. Their coefficients have magnitudes and signs similar to those seen in Table 4, so our general interpretations apply without change to this subsample. Mixed $(n=143)$ : $\quad$ The coefficients on age, grades and grandpar resemble their counterparts in Table 4, although given the smaller sample, only grandpar remains significant. Female, language and parents appear relatively unimportant for this group.

Non-Natives $(n=74)$ : Female, grades and language all exhibit stronger effects that those in the fullsample analysis of Table 4, but only grades reaches statistical significance. The age, parents and grandpar variables appear unimportant.

Although necessarily tentative, the subsample analysis adds details to our understanding of the full-sample results. Parents' and especially grandparents' encouragement matters to Native and mixedidentity youth, whereas non-Native youth take encouragement more directly from their own academic performance. The Native language effect found even among non-Natives supports interpretation of this measure partly as an academic achievement. Decline of college ambitions with increasing age characterizes Native and mixed-identity students, but not the non-Natives.

An alternative explanation for the importance of grandparents' opinions among Native and mixed-identity students might be that they more often live in their birth communities, and hence near to the older generation. Native and mixed-identity youth were only slightly more likely to report that their 
grandparents currently lived in their household (12 or $13 \%$ versus $8 \%$ ); but were much more likely to be living in their own community of birth $(66 \%$ of Natives, $55 \%$ of mixed-identity students, compared with $25 \%$ of non-Natives).[7] To test whether ethnicity or grandparent effects on college plans are confounded by length of residence in the community, we performed regressions (not shown) similar to models 3 and 4 but including a dummy variable indicating place of birth. Being born in the present community had no independent effect on college plans $(P>.8)$, and its inclusion did not change other substantive findings.

Finally, a sizable gender difference exists among both Native and non-Native students (as depicted in Figure 4, a smaller difference exists within the mixed-identity subsample too). This gender difference therefore cannot be explained solely with reference to unique aspects of Alaska Native culture or circumstances. That conclusion fits with other recent studies showing disproportionate female outmigration from northern communities in Newfoundland, Norway, Greenland and elsewhere.

\section{DISCUSSION}

Over the course of this research, principal investigators made repeated visits and spoke with students, educators and others in all of the studied communities. From many sources we heard that parents' and even grandparents' attitudes towards education matter greatly in rural Alaska. More generally, the literature supports this claim (e.g. Coleman 1988; Cobb et al. 1989; Majoribanks 1992; Spencer and Markstrom-Adams 1990). Family opinions cut two ways. Some students described their families as pro-education, urging them to study hard and go to college so that they could get a good job. Others said their families saw less need for schooling or were negative about college, because it would remove them from family and village life. Several graduates who did attend college mentioned receiving letters from home, in which relatives suggested that they should drop out and come back home because the family needed them. To any adolescents, and especially to those struggling with unfamiliar demands and discipline at a faraway school, such appeals might be hard to resist.

Our preliminary analysis found that students who identify themselves as Natives are less likely to plan to leave rural Alaska for the predominantly non-Native worlds of college or cities. But the effects of ethnicity appear largely indirect, operating through the ways that families encourage or provide role models for their children's educational aspirations. Thus in a multivariate analysis, parents' and grandparents' support for college, in particular, explain much of the difference between the ethnic groups' aspirations.

These findings likely reflect a combination of several forces. When young people perceive their parents and grandparents as favoring their college attendance, they may gain confidence from that trust and commitment in them and absorb those aspirations for themselves. Their tool kit includes an image of themselves as college students. The strong effect of grandparents' support among Native and mixedidentity youth, in particular, could also reflect a more fundamental aspect of culture. Among Native students, grandparents who support college goals for their grandchildren might enhance the legitimacy of these goals because as elders they, even more than parents, represent the cultural identity the youth holds. Among students with a mixed background, Native grandparents supporting college may give a sort of cultural "permission" to participate in social change. Support for college by non-Native grandparents of mixed-identity students coincides with the identity the young person has chosen for him or herself. Among non-Native students, as this interpretation predicts, we found no comparable grandparent effect.

Recent work by Farkas (1996) attributes ethnic differences in educational attainment and wages to the ways in which cultural resources are acquired in families at an early age. Following Swidler (1986) and Ogbu (1986), he argues that parental skills, habits and styles shape young children's skills, and their expectations that they can succeed when they acquire these skills. His argument might apply here. Those rural Alaska parents and grandparents who support education, and thus greater acculturation, create an environment in which pursuing college and even moving to the city are both 
accepted and considered viable future paths for their children and grandchildren. The children absorb these views, making college seem feasible to them too. When parents or grandparents in Native or mixed-identity families embrace college as a goal, they are directly giving permission to the youth to aspire to college. Indirectly, their own worldview has equipped the youth's tool kit for this future in small ways every day.

Permitting respondents to select compound ethnic identities changed the overall picture of schools' enrollment, mainly by reducing the proportion depicted simply as Native. In several analyses, mixed-identity students displayed characteristics intermediate between those of Native and non-Native students. These findings support arguments that for at least some research and policy purposes, ethnicity should be conceived as a matter of degree, on one or more underlying dimensions, instead of the usual exclusive categories.

Our analysis of high school students' college plans complements Barnhardt's (1994) study of Native graduates from the University of Alaska Fairbanks. The high drop-out rate among Native college students arose, she concludes, in part because of conflicts between Native cultural values and the values embedded in western institutions such as universities. Students need to integrate these diverse values in order to succeed in university settings. Among the primary reasons students cited for their decisions to attend college in the first place were parents' and grandparents' beliefs in education. High levels of support from family and friends were also associated with more positive early experiences at UAF.[8]

A combination of high secondary-school graduation rates with low test scores foreshadows the troublesome transition experienced by some young adults. Our studies found that large proportions of bush youth say they want and expect to leave their home communities after high school, to find jobs or attend college. Many of them, however, find these goals unexpectedly hard to achieve. Their dilemma suggests misunderstandings about, and lack of preparation for, life outside of the bush. Educators concerned with such preparation face the challenge of trying to encourage self-confidence without minimizing the real obstacles students will encounter, or their need to continue a sustained effort through difficult, intermediate steps. Television entertainment, with its famous characters and lifestyles that contrast so strikingly with village life, conveys a powerful countermessage of desirable ends earned by no visible means.

Unlike the ethnicity differences, gender differences in college aspirations did not fade when we controlled for family or individual tool-kit type variables. Gender differences consequently require different explanations, parallel to those offered for female outmigration. Disproportionate female outmigration is a widespread phenomenon that has been observed in small communities of other northern regions including the Canadian Arctic (Condon 1987; Kochmer and Johnson 1995), Greenland (Langaard 1986; Hamilton et al. 1996), rural Ireland (Messenger 1969; Scheper-Hughes 1979), Finnish Samiland (Pelt 1973), Newfoundland outports (Seyfrit 1993; Hamilton and Seyfrit 1994c) and Norwegian fishing villages (Jentoft 1993; Hamilton and Otterstad 1997). Lower-latitude examples could be found as well. We suggest that the causes of this female outmigration include a mix of cultural and structural factors: 1. Education, and the jobs that require education (for example, in the North's booming public sectors), are often perceived to fit more closely with traditional female roles and behavior than with those of males. When women therefore pursue education farther than men, or show longer employment stability, this enhances their relative chances for economic and geographic mobility.

2. Conversely, the job and recreation opportunities available in isolated rural areas (e.g., temporary construction; hunting and fishing; village basketball games) tend to appeal most strongly to males.

3. Given a choice between the roles and economic opportunities they see for women in a small traditional community, and those in a modern city, some women "vote with their feet" in favor of urban life. 
4. The flow of outsiders moving temporarily into northern communities tends to be predominantly male. This creates opportunities for outside male/local female marriages, with some likelihood that the couple will eventually move away. Besides the geographic change, such marriages also affect the cultural tool kits of both the individuals and their children.

Similar general conditions might be found in many rural societies exposed to rapid modernization.[9] The gender differences we found in both outmigration and educational plans might be viewed more broadly as indicators of a difference in responses to modernization and social change.

\section{REFERENCES}

Alaska Federation of Natives. 1989. The AFN Report on the Status of Alaska Natives: A Call for Action. Anchorage: Alaska Federation of Natives.

Barnhardt, Carol. 1994. Life on the Other Side: Alaska Native Students and the University of Alaska Fairbanks. Ph.D. dissertation, University of British Columbia.

Beaulieu, L. J., and D. Mulkey. 1995. "Human capital in rural America: A review of theoretical perspectives." Pp. 3-21 in Investing in People: The Human Capital Needs of Rural America, edited by L. Beaulieu and D. Mulkey. Boulder, CO: Westview Press.

Becker, G. S.. 1962. Human Capital. Chicago: University of Chicago Press.

Bernstein, B. 1971. Class, Codes, and Control. London: Routledge \& Kegan Paul.

Bourdieu, Pierre. 1986. "The forms of capital." In Handbook of Theory and Research for the Sociology of Education, edited by J. G. Richardson. New York: Greenwood Press.

Chance, Norman A. 1990. The Inupiat and Arctic Alaska: An Ethnography of Development. Fort Worth: Holt, Rinehart and Winston.

Chance, Norman A., and E. N. Andreeva. 1995. "Sustainability, equity, and natural resource development in Northwest Siberia and Arctic Alaska." Human Ecology 23(2):217-240.

Cobb, R. A., W. G. McIntyre, and P. A. Pratt. 1989. "Vocational and educational aspirations of high school students: a problem for rural America." Research on Rural Education 6(2):11-15.

Coleman, J. S. 1988. "Social capital in the creation of human capital." American Journal of Sociology 94:95-120.

Coleman, J. S. 1990. Foundations of Social Theory. Cambridge, MA: Belknap Press of Harvard University.

Condon, Richard G. 1987. Inuit Youth: Growth and Change in the Canadian Arctic. New Brunswick: Rutgers University Press.

Darnell, Frank and Anton Hoëm. 1996. Taken to Extremes: Education in the Far North. Oslo: Scandinavian University Press.

Duncan, Cynthia M. 1996. "Understanding persistent poverty: Social class context in rural communities." Rural Sociology 61(1):103-124.

Farkas, George. 1996. Human Capital or Cultural Capital: Ethnicity and Poverty in an Urban School District. New York: Adline de Gruyter. 
Fernandez-Kelly, M. P. 1995. "Social capital and cultural capital in the urban ghetto: Implications for economic sociology and immigration.” In Economic Sociology, edited by A. Portes. New York: Russell Sage.

Fienup-Riordan, Ann. 1990. Eskimo Essays: Yup'ik Lives and How We See Them. New Brunswick: Rutgers University Press.

Fogel-Chance, Nancy. 1993. "Living in both worlds: 'Modernity' and 'tradition' among North Slope Inupiat women in Anchorage." Arctic Anthropology 30(1):94-108.

Furstenberg, Jr, F. and M.E. Hughes. 1995. "Social capital and successful development among at-risk youth.” Journal of Marriage and the Family 57:580-592

Grimes, Jody. 1997. Community Context and Academic Outcomes in Alaskan School Districts. Master's Thesis in Sociology, University of New Hampshire.

Hamilton, Lawrence C., Rasmus O. Rasmussen, Nicholas E. Flanders, and Carole L. Seyfrit. 1996. "Outmigration and gender balance in Greenland." Arctic Anthropology 33(1):89-97.

Hamilton, Lawrence C. and Carole L. Seyfrit. 1993a. "Town-village contrasts in Alaskan youth aspirations." Arctic 46(3):255-263.

Hamilton, Lawrence C. and Carole L. Seyfrit. 1993b. "Interpreting multinomial logistic regression." Stata Technical Bulletin 13(May):24-28.

Hamilton, Lawrence C. and Carole L. Seyfrit. 1994a. "Female flight? Gender balance and outmigration by Native Alaskan villagers." Arctic Medical Research 53(Supplement 2):189-193.

Hamilton, Lawrence C. and Carole L. Seyfrit. 1994b. "Coming out of the country: community size and gender balance among Alaskan Natives." Arctic Anthropology 31(1):16-25.

Hamilton, Lawrence C. and Carole L. Seyfrit. 1994c. "Resources and hopes in Newfoundland." Society and Natural Resources 7:561-578.

Hamilton, Lawrence C., Carole L. Seyfrit and Christina Bellinger. 1997. "Environment and sex ratios among Alaska Natives: An historical perspective." Population and Environment 18(3):283-299.

Hamilton, Lawrence C. and Oddmund Otterstad. 1997. "Sex ratios and community size: Notes from the northern Atlantic." Population and Environment.

Hosmer, David W. and Stanley Lemeshow. 1989. Applied Logistic Regression. New York: Wiley Interscience.

Hower, Wendy and Kristan Kelly. 1996. “On the Edge: Do Bush Schools Measure Up?” Special Limited Edition Reprint. Fairbanks Daily News-Miner, January 21-26.

Jacobs, J., D. Karen, and K. McClelland. 1991. “The dynamics of young men's career aspirations.” Sociological Forum 6(4)609-639.

Jentoft, Svein. 1993. Dangling Lines: The Fisheries Crisis and the Future of Coastal Communities. St. John's, Newfoundland: Institute of Social and Economic Research, Memorial University of Newfoundland.

Jorgensen, Joseph G. 1990. Oil Age Eskimos. Berkeley: University of California Press. 
Kerckhoff, A. 1977. "The realism of educational ambitions in England and the United States." American Sociological Review 42:563-571.

Kerckhoff, A. 1984. “The current state of social mobility research.” Sociological Quarterly 25:139-153.

Kleinfeld, Judith. 1981. "Different paths of Inupiat men and women in the wage economy." Alaska Review of Social and Economic Conditions 18(1).

Kleinfeld, Judith. 1992. Alaska Native Education: Issues in the Nineties. Anchorage: Institute of Social and Economic Research, University of Alaska Anchorage.

Kleinfeld, Judith, Lee Gorsuch and Jim Kerr. 1986. Minorities in Higher Education: The Changing North. Fairbanks: Institute of Social and Economic Research.

Knight, Dorothy M. 1994. Summary of Alaska's Public School Districts' Report Cards to the Public, School Year 1992-93. Juneau: Alaska Department of Education.

Kochmer, Jonathan P. and Darryll R. Johnson. 1995. "Demography and socioeconomics of northern North America: Current status and impacts of climate change." Pp. 31-54 in Human Ecology and Climate Change: People and Resources in the Far North, edited by D. L. Peterson and D. R. Johnson. Washington, DC: Taylor and Francis.

Langaard, P. 1986. "Modernization and traditional interpersonal relations in a small Greenlandic community: A case study from southern Greenland." Arctic Anthropology 27(1):20-35.

Lichter, D. T., G. T. Cornwall, and D. J. Eggebeen. 1993. "Harvesting human capital: Family structure and education among rural youth." Rural Sociology 58(1):53-75.

Long, J. Scott. 1997. Regression Models for Categorical and Limited Dependent Variables. Thousand Oaks, CA: Sage.

Loury, G. 1977. "A dynamic theory of racial income differences." Ch. 8 in Women, Minorities, and Employment Discrimination, edited by P.A. Wallace and A. Le Mund. Lexington, MA: Lexington Books.

Loury, G. 1987. "Why should we care about social inequality?" Social Philosophy and Policy 5:249-271.

Majoribanks, Kevin. 1972. "Ethnic and environmental influences on mental abilities." American Journal of Sociology 78(2):323-37.

McLanahan, S. and G. Sandefur. 1994. Growing Up with a Single Parent. Cambridge: Harvard University Press.

Messenger, John C. 1969. Inis Beag, Isle of Ireland. New York: Holt, Rinehart and Winston.

Ogbu, John. 1986. "The consequences of the American caste system." Pp. 19-56 in The School Achievement of Minority Children, edited by U. Neisser. Hillsdale, NJ: Lawrence Erlbaum.

Pelto, Pertti J. 1973. The Snowmobile Revolution: Technology and Social Change in the Arctic. Menlo Park, CA: Cummings.

Portes, A. and J. Sensenbrenner. 1993. "Embeddedness and immigration: Notes on the social determinants of economic action." American Journal of Sociology 98(6):1320-1350. 
Scheper-Hughes, Nancy. 1979. Saints, Scholars, and Schizophrenics: Mental Illness in Rural Ireland. Berkeley: University of California Press.

Seyfrit, Carole L. 1993. Hibernia's Generation: Social Impact of Oil Development on Adolescents in Newfoundland. ISER Offshore Oil Project Series. St. John's, NF: Institute of Social and Economic Research, Memorial University of Newfoundland.

Seyfrit, Carole L., Christine R. Crossland, and Lawrence C. Hamilton. 1996. "Alcohol, drugs, and family violence: perceptions of high schools students in southwest Alaska." Paper presented at the 10th International Congress on Circumpolar Health, Anchorage, May.

Seyfrit, Carole L., and Lawrence C. Hamilton. 1992. "Social impacts of resource development on Arctic adolescents." Arctic Research of the United States 6(Fall):57-61.

Seyfrit, Carole L. and Lawrence C. Hamilton. 1997. "Alaska Native youth and their attitudes toward education.” Arctic Anthropology 34(1):in press.

Smith, M. H., L. J. Beaulieu, and G. D. Israel. 1992. "Effects of human capital and social capital on dropping out of high school in the South." Journal of Research in Rural Education 8(1):75-88.

Spencer, M. B. and C. Markstrom-Adams. 1990. "Identity processes among racial and ethnic minority children in America." Child Development 61:290-310.

Swidler, A. 1986. "Culture in action: Symbols and strategies." American Sociological Review 51:273-286.

Willis, P. 1977. Learning to Labor: How Working Class Kids Get Working Class Jobs. New York: Columbia university Press.

Zhou, Min and Carl L. Bankston III. 1994. "Social capital and the adaptation of the second generation: The case of Vietnamese youth in New Orleans.” International Migration Review 28(4):821-845. 


\section{TABLES AND FIGURES}

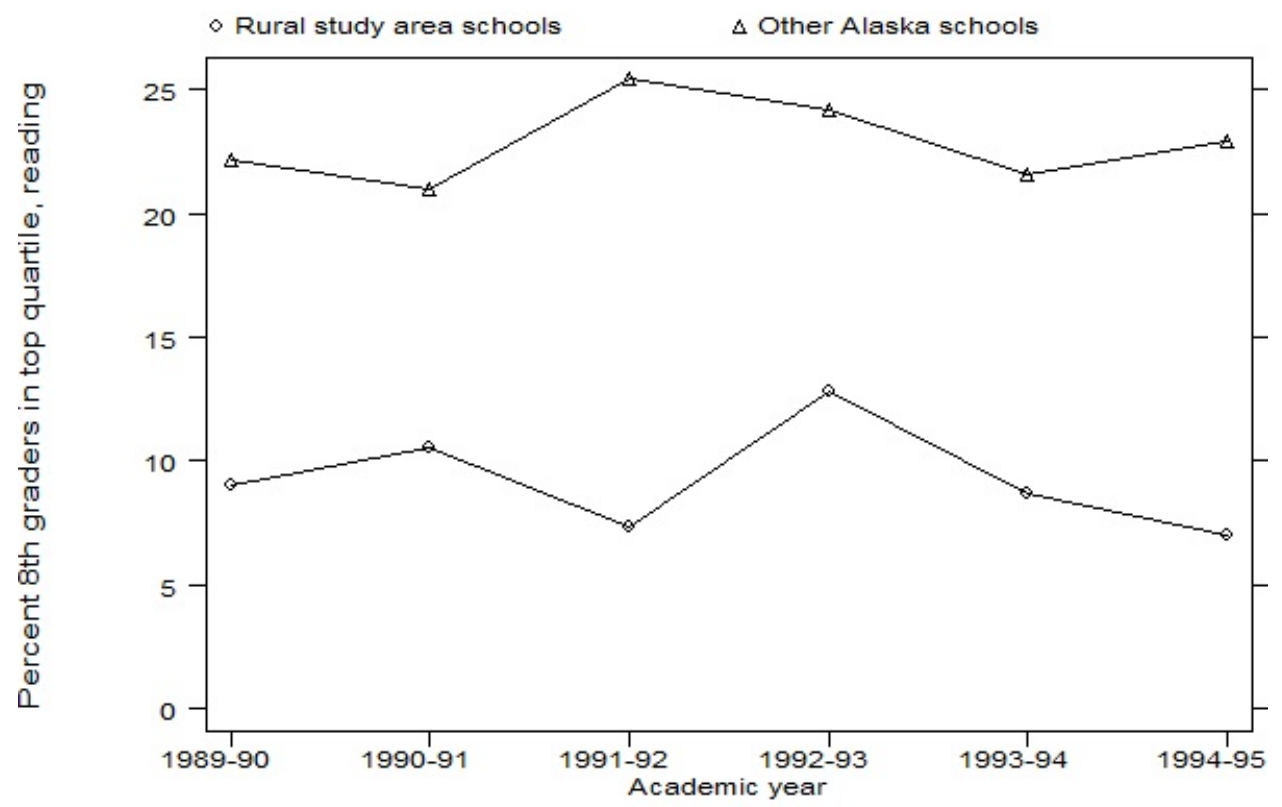

Figure 1: $\quad$ Trends in the mean percentage of 8th graders scoring in top quartile on standardized reading tests.
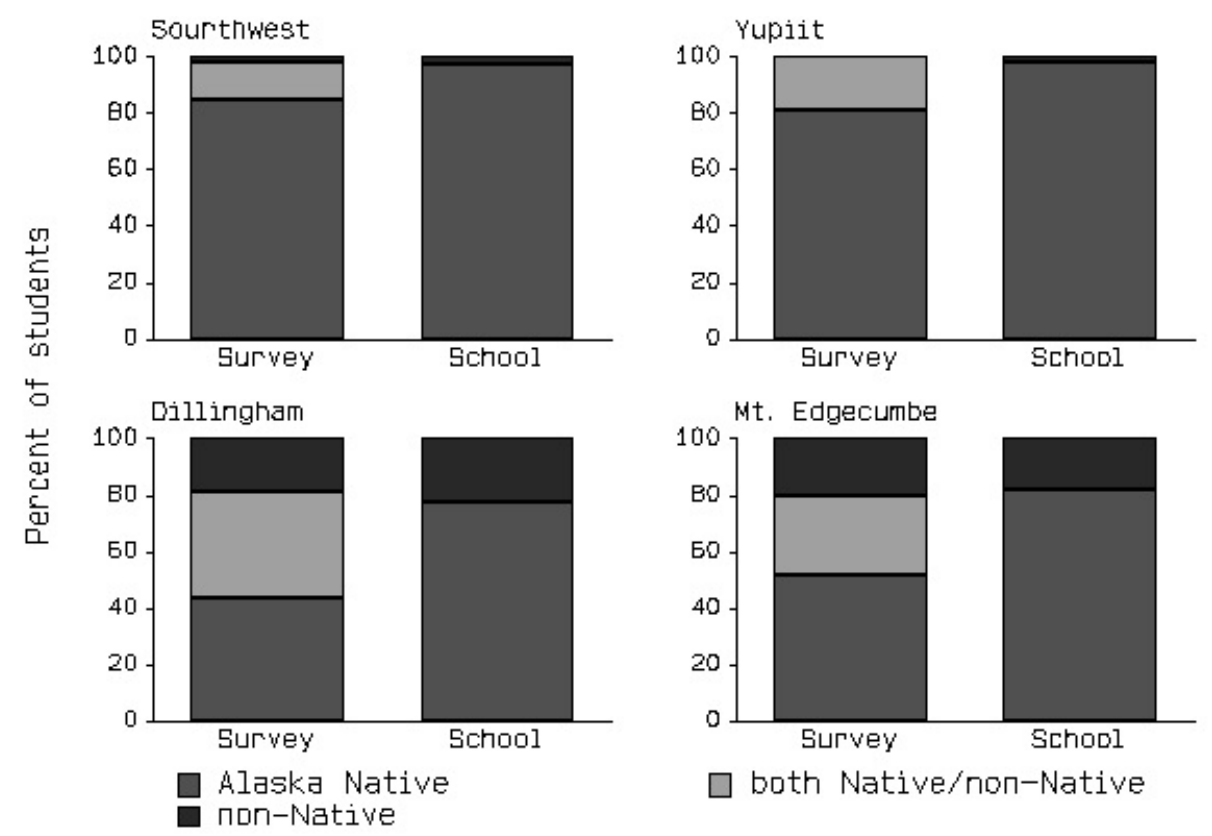

$\square$ both Native/non-Native

Figure 2: $\quad$ Ethnic identity of students as reported by students (left bar in each pair) and by school districts. 




Figure 3: $\quad$ Percent students expecting to live most of their lives outside the region, by gender and ethnic self-identification.

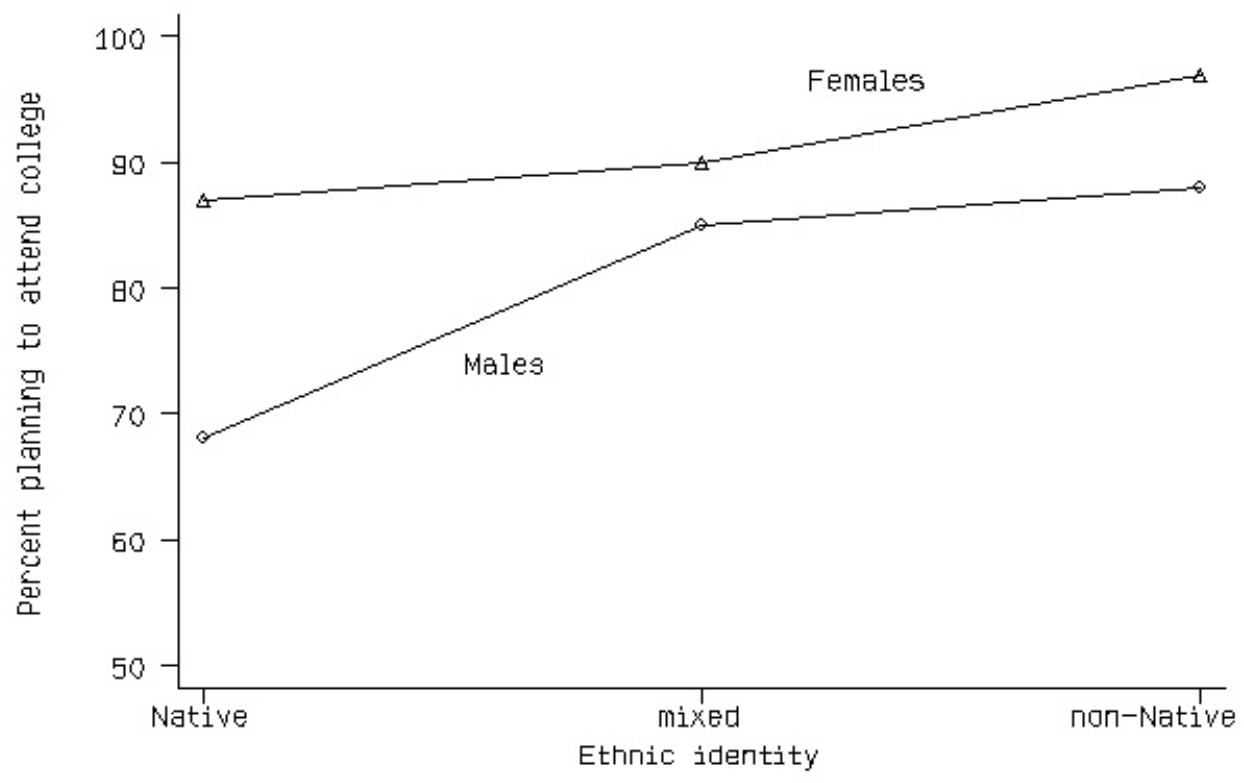

Figure 4: $\quad$ Percent students planning to attend college, by gender and ethnic self-identification. 
Table 1: Characteristics of rural study area (Northwest Arctic, Yupiit, Dillingham and Southwest) and other Alaska school districts.

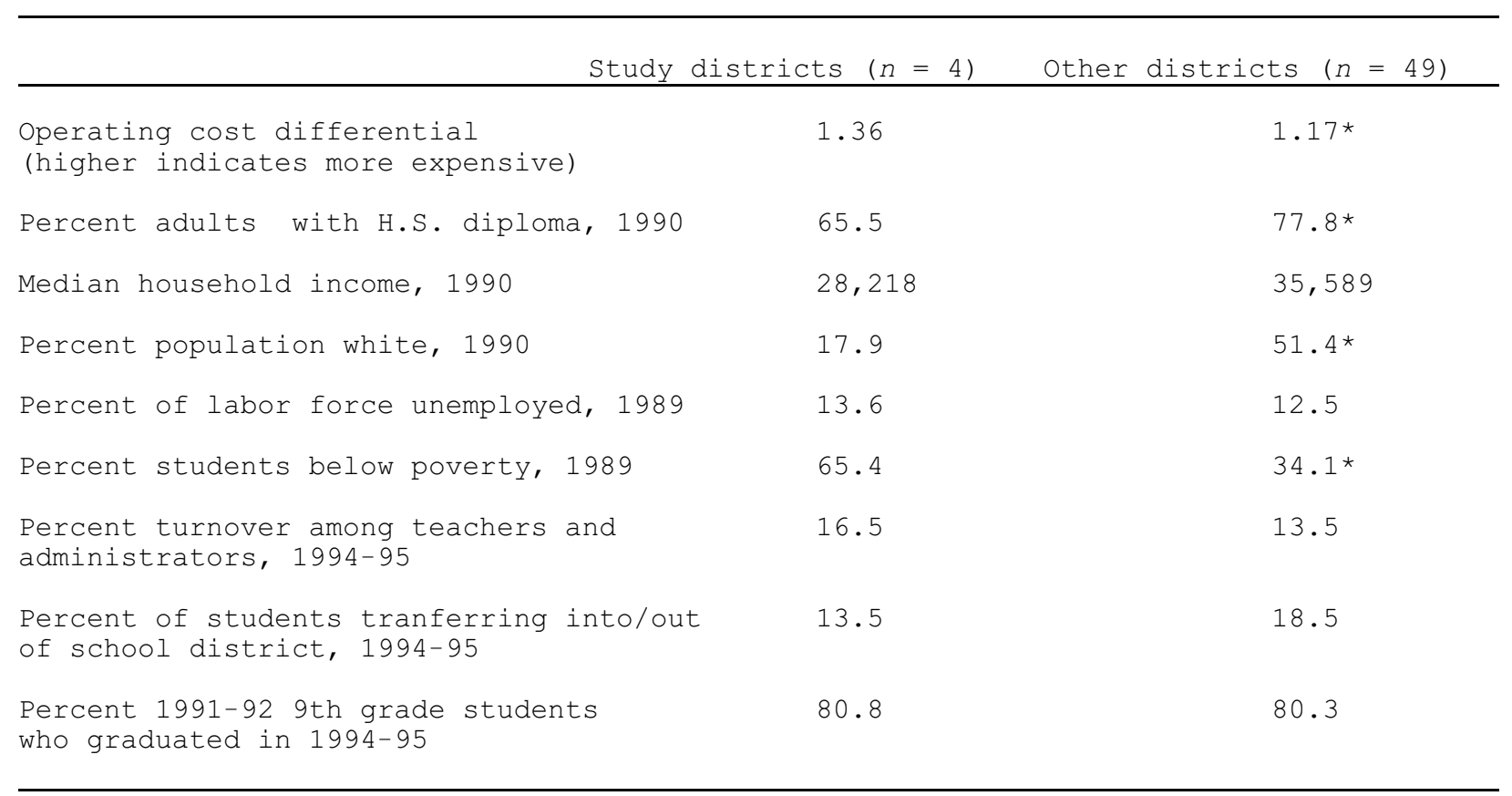

*Means differ significantly at the $\alpha=.05$ level. 
Table 2: $\quad$ Ethnic self-identification of students in 1995 survey.

Do you consider yourself to be mainly:

\begin{tabular}{rlrlrl} 
Alaska Native & Not an Alaska Native & Both, please describe \\
\cline { 2 - 3 } & & 1\% & Asian/Pacific Islander & 16\% wrote in some \\
$6 \%$ & Aleut & $<1 \%$ & Black & explanation, e.9. \\
$3 \%$ & Athabaskan & $1 \%$ & Hispanic & simple statements \\
$32 \%$ & Inupiat & $23 \%$ & White & such as "Aleut, \\
$2 \%$ & Tlingit or Haida & Yupik, White" or \\
30 & Yupik & $2 \%$ & American Indian & "My father is white, \\
$8 \%$ & other & & other & mother is 1/2 white
\end{tabular}

Many students gave answers in more than one column, or gave more than one answer within a column. After examining all of these individually we summarized students' ethnic self-identification as follows:

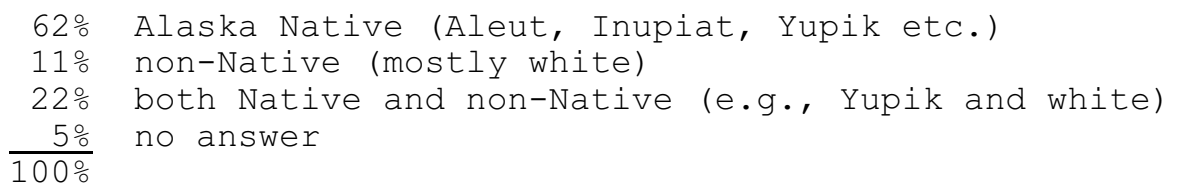


Table 3: Selected variables from the 1995 Alaska Youth Survey.




Table 4: Logistic regressions of "plan to attend college or university" (college) on ethnic identity, demographic, and cultural tool kit predictors.

\begin{tabular}{|c|c|c|c|c|}
\hline $\begin{array}{l}\text { Predictor } \\
\text { Model } 4\end{array}$ & Model 1 & Model 2 & Model 3 & \\
\hline \multicolumn{5}{|l|}{ Ethnic identity } \\
\hline native & $-1.407 \star \star$ & $-.986 *$ & -.216 & -.407 \\
\hline mixed & -.803 & -.556 & -.211 & -.196 \\
\hline \multicolumn{5}{|l|}{ Demographic } \\
\hline female & $.914 * \star$ & $.740 * \star$ & $.868 * \star$ & $.555 *$ \\
\hline age & $-.218 * \star$ & $-.273 \star \star$ & -.153 & $-.230 *$ \\
\hline \multicolumn{5}{|l|}{ Tool kit } \\
\hline \multicolumn{5}{|l|}{$\overline{\text { Individual }}$} \\
\hline grades & & $.905 * *$ & $.801 * *$ & $.667 * \star$ \\
\hline language & & .108 & $.615 \star \star$ & $.471 *$ \\
\hline \multicolumn{5}{|l|}{ Family } \\
\hline parents & & & $.910 * *$ & $.967 * *$ \\
\hline grandpar & & & $.983 * \star$ & $.977 \star \star$ \\
\hline pared & & & $.152 \star$ & \\
\hline$n$ of cases & 677 & 658 & 480 & 613 \\
\hline pseudo $R^{2}$ & .068 & .105 & .293 & .260 \\
\hline
\end{tabular}

$\star P<.05$ (two-tail test)

$\star \star P<.01$ (two-tail test) 


\section{NOTES}

1. Darnell and Hoëm (1996) provide an organizational description of education in Alaska and other Arctic regions.

2. Individuals can move many times during their lives, and in Alaska they often do. A pattern of leaving the bush for a while, but then returning, is particularly common. Some individuals have the goal of obtaining training or education elsewhere, then coming back to apply their new skills near home. For others, these movements seem to happen without planning. In our surveys we measured migration expectations by asking where students expect to live "most of the rest of their lives." Many more students said they expect such long-term migration, than one might guess by looking at how many of their peers actually have moved and stayed away.

3. The majority of non-Native students in schools we studies are children of families who are not long-term or permanent residents of that community. Consequently, their expectations of eventually moving away are influenced by a variety of factors besides those discussed in our analysis. Some differences between ethnic groups are explored in the section on predictors of college aspirations.

4. Pseudo $\mathrm{R}^{2}$ equals 1 - model log likelihood/intercept-only log likelihood (for a discussion of this and similar measures, see Long 1997:104). It provides a proportional-reduction-in-error statistic for maximum-likelihood models, roughly analogous to the true $\mathrm{R}^{2}$ statistic employed with least-squares models.

5. The survey also asked open-ended questions about mother's and father's occupation, which in some studies might have served as rough proxies for their education. That substitution was not practical with these data, given the limited opportunities for village employment and the large number of missing values.

6. We do not show a formal path model in this paper, but did estimate one for our own analysis through a combination of dichotomous and ordinal logistic methods. The results agreed that ethnicity's effects are primarily indirect, through grades, parents and grandpar.

7. By "birth community" we refer not to the place where respondents were literally born, which could often be a regional hospital, but rather to the place where their parents were living at the time they were born.

8. Barnhardt also notes the analytical difficulties caused by a lack of "multi" or "bi" racial categories in UAF documents.

9. Although female outmigration represents a widespread pattern, it is not universal. For example, Hamilton and Otterstad (1997) found evidence of a negative correlation between young adult percent female and community size in Norway, Iceland and Newfoundland - but not in the U.S. state of Maine. Much comparative work could be done on its causes and consequences across different cultural settings. 